\title{
Does Somatostatin or Gastric Inhibitory Peptide Receptor Expression Correlate with Tumor Grade and Stage in Gut Neuroendocrine Tumors?
}

\author{
Meike Körner Beatrice Waser Jean Claude Reubi \\ Division of Cell Biology and Experimental Cancer Research, Institute of Pathology, University of Bern, \\ Bern, Switzerland
}

\begin{abstract}
Key Words
Somatostatin receptor $\cdot$ Gastric inhibitory peptide receptor $\cdot$ Neuroendocrine tumor $\cdot$ MIB-1 proliferation index $\cdot$ Receptor autoradiography
\end{abstract}

\begin{abstract}
Background/Aims: Important characteristics of neuroendocrine neoplasms (NEN) for prognosis and therapeutic decisions are the MIB-1 proliferative index (tumor grade) and tumor stage. Moreover, these tumors express peptide hormone receptors like somatostatin and gastric inhibitory peptide (GIP) receptors which represent important established and potential future targets, respectively, for molecular imaging and radiotherapy. However, the interrelation between tumor proliferation, stage, and peptide receptor amounts has never been assessed. Methods: In 114 gastrointestinal and bronchopulmonary NEN, the proliferative rate assessed with MIB-1 immunohistochemistry and tumor stage were compared with the somatostatin type 2 receptor (sst2) and GIP receptor expression measured quantitatively with in vitro receptor autoradiography. Results: NEN generally showed high sst2 and GIP receptor expression. GIP receptor but not sst2 expression correlated with the MIB-1 index. GIP receptor levels gradually increased in a subset of
\end{abstract}

insulinomas and nonfunctioning pancreatic NEN, and decreased in ileal and bronchopulmonary NEN with increasing MIB-1 rate. MIB-1 levels were identified, above which GIP receptor levels were consistently high or low. These MIB-1 levels were clearly different from those defining tumor grade. In grade 3 NEN, GIP receptor levels were always low, while sst2 levels were variable and sometimes extremely high. Conversely, sst2 expression correlated more frequently with tumor stage than GIP receptor expression, with metastasized NEN showing higher sst2 levels than localized tumors. Conclusions: sst2, a clinically crucial molecular target, shows variable and unpredictable expression in NEN irrespective of tumor grade. Therefore, each NEN should be tested for sst2 if clinical applications with somatostatin analogs are considered. Conversely, the potential future role of GIP receptors as molecular targets in NEN may be dependent on the MIB-1 level.

(c) 2015 S. Karger AG, Basel

\section{Introduction}

Gut and extraintestinal neuroendocrine neoplasms (NEN) represent challenging tumors in terms of clinical management and research due to various features such as

\section{KARGER 125}

(C) 2015 S. Karger AG, Basel

0028-3835/15/1011-0045\$39.50/0

E-Mail karger@karger.com

www.karger.com/nen
Meike Körner, MD

Division of Cell Biology and Experimental Cancer Research

Institute of Pathology, University of Bern

Murtenstrasse 31, CH-3010 Bern (Switzerland)

E-Mail meike.koerner@pathology.unibe.ch 
rarity, heterogeneity with respect to site of origin and hormone production, slow growth and progression, and metastatic potential. However, biological characterization of individual tumors is significantly improved by determining specific prognostic and predictive markers.

Important prognostic factors for NEN are tumor grade and stage. The grade is based on the proliferative activity of the tumor assessed by the mitotic rate or by Ki-67 immunohistochemistry. The stage reflects tumor size, invasiveness, and presence of nodal and distant metastasis, and is described in the TNM classification. Both grade and stage correlate well with prognosis [1-3]. They are essential criteria for a standardized patient management $[4,5]$ as well as represent a basis for the comparability of clinical studies. Therefore, various comparable consensus guidelines for the grading and staging of NEN were developed in the last years, such as those by the ENETS, NANETS, WHO, and AJCC [6-10], and have been widely adopted since.

Lately, particular attention has been paid to the proliferative index assessed by Ki-67 immunohistochemistry as a marker of tumor biology and prognosis. Indeed, the Ki67 index has been shown to strongly correlate with survival $[3,11]$. However, its value is limited due to interlaboratory and interobserver variability in the $\mathrm{Ki}-67$ assessment [12] and a potential sampling bias in small biopsy specimens. Likewise, the significance of tumor grade may be limited since tumor grade is defined by arbitrary Ki-67 cutoff values used for tumor grading [13], and grade 2 tumors comprise a large spectrum of Ki-67 positivity rate, ranging from 2 to $20 \%$.

NEN are also characterized by the high expression of peptide hormone receptors. These are markers predictive of the suitability of an individual tumor for an in vivo targeting with radiolabeled peptide analogs for imaging and therapeutic purposes [14]. Of importance, the success of peptide receptor targeting of NEN strongly correlates with the amount of tumoral peptide receptors. Clinically best established is targeting of somatostatin receptors, which are typically expressed at high levels and in high incidence in NEN $[15,16]$. A promising new candidate for such a NEN targeting with radioactive compounds is the gastric inhibitory peptide (GIP) receptor which was only recently found to be universally overexpressed in gut and lung NEN [17]. In vivo GIP receptor targeting of tumors was successful in animals in xenografted tumors expressing GIP receptors [18], but has not yet been tested in human patients.

Although it is known that somatostatin and GIP receptors are widely expressed in gut and lung NEN, a sys- tematic correlation between quantitative levels of these predictive markers and the proliferative index as a biological and prognostic marker has, to our knowledge, not yet been performed. At present, it is generally assumed that high-grade tumors are not suitable for somatostatin receptor targeting because of a low somatostatin receptor incidence and density $[5,19]$. Somatostatin receptor imaging is, therefore, recommended only for grade 1 and 2 tumors, but considered optional for grade 3 tumors [20]. However, published objective data to support a generally low somatostatin receptor expression in tumors with high proliferative rates are scarce. Likewise, it is unknown if somatostatin and GIP receptor expression levels also correlate with proliferation in grade 1 and 2 tumors or with metastatic behavior. Therefore, the aim of the present study was to compare somatostatin and GIP receptor levels measured quantitatively by in vitro receptor autoradiography in resected tumor specimens with the immunohistochemical proliferative index and tumor stage in common gut and lung NEN. Since NEN represent an anatomically and biologically heterogeneous tumor group, NEN of different sites of origin and with different hormone production were analyzed separately.

\section{Materials and Methods}

\section{Tumors}

A total of 114 NEN of gastroenteropancreatic and bronchopulmonary origin were investigated. These included 20 ileal NEN, 17 nonfunctioning pancreatic NEN, 53 functioning pancreatic NEN (40 insulinomas, 5 gastrinomas, 3 glucagonomas, 5 VIPomas), 1 duodenal gastrinoma, and 23 bronchopulmonary carcinoids. All tumors were primaries except for 5 cases, which included liver metastases of an ileal NEN, a nonfunctioning pancreatic NEN and a VIPoma, as well as lymph node metastases of an insulinoma and a bronchopulmonary carcinoid. The majority of the tumors had been analyzed previously for peptide receptors [17, 21-24]. In particular, GIP receptor expression of most cases has been published previously [17], except for 4 cases. The remaining tumors had been collected newly at the Institute of Pathology of the University of Bern. Informed consent was obtained from all patients. The study collection conformed to the ethical guidelines of and was reviewed by the Institutional Review Board.

Tumor grade of the gastroenteropancreatic NEN was determined using MIB-1 immunohistochemistry according to Rindi et al. $[6,25]$ (grade 1 : MIB- $1 \leq 2 \%$; grade 2 : MIB- $1>2-20 \%$; grade 3 : MIB-1 $>20 \%)$. Bronchopulmonary carcinoid tumors were graded similarly, although the immunohistochemical proliferative index is not yet established for grading NEN at this site [26]. Where available, the TNM stage was retrieved from the patient records. Tumors were divided into those without evidence of metastasis (N0 $\mathrm{M} 0)$ and those with nodal and/or distant metastases $(\mathrm{N}+$ and/or $\mathrm{M}+)$.
Körner/Waser/Reubi 
Fig. 1. Relationship between the MIB-1 proliferative index (\%; $\mathrm{x}$-axis) and ${ }^{125} \mathrm{I}$ [Tyr3]-octreotide and ${ }^{125} \mathrm{I}-\mathrm{GIP}(1-30)$ binding density levels (dpm/mg tissue; $y$ axis) in individual NEN. Above a cutoff value of $3,000 \mathrm{dpm} / \mathrm{mg}$ radioligand binding density, receptor levels were considered high. All ileal NEN with MIB- $1 \geq 16 \%$ as well as bronchial NEN with MIB-1 $\geq 8 \%$ show low or no GIP receptor expression. Conversely, all grade 2 nonfunctioning pancreatic NEN with MIB- $1>5 \%$ and $>2 \%$ show high sst 2 and GIP receptor levels, respectively. Insulinomas with MIB-1 between 2 and $5 \%$ show either no or extremely high sst2 levels, but more variable GIP receptor levels. GI = Gastrointestinal.
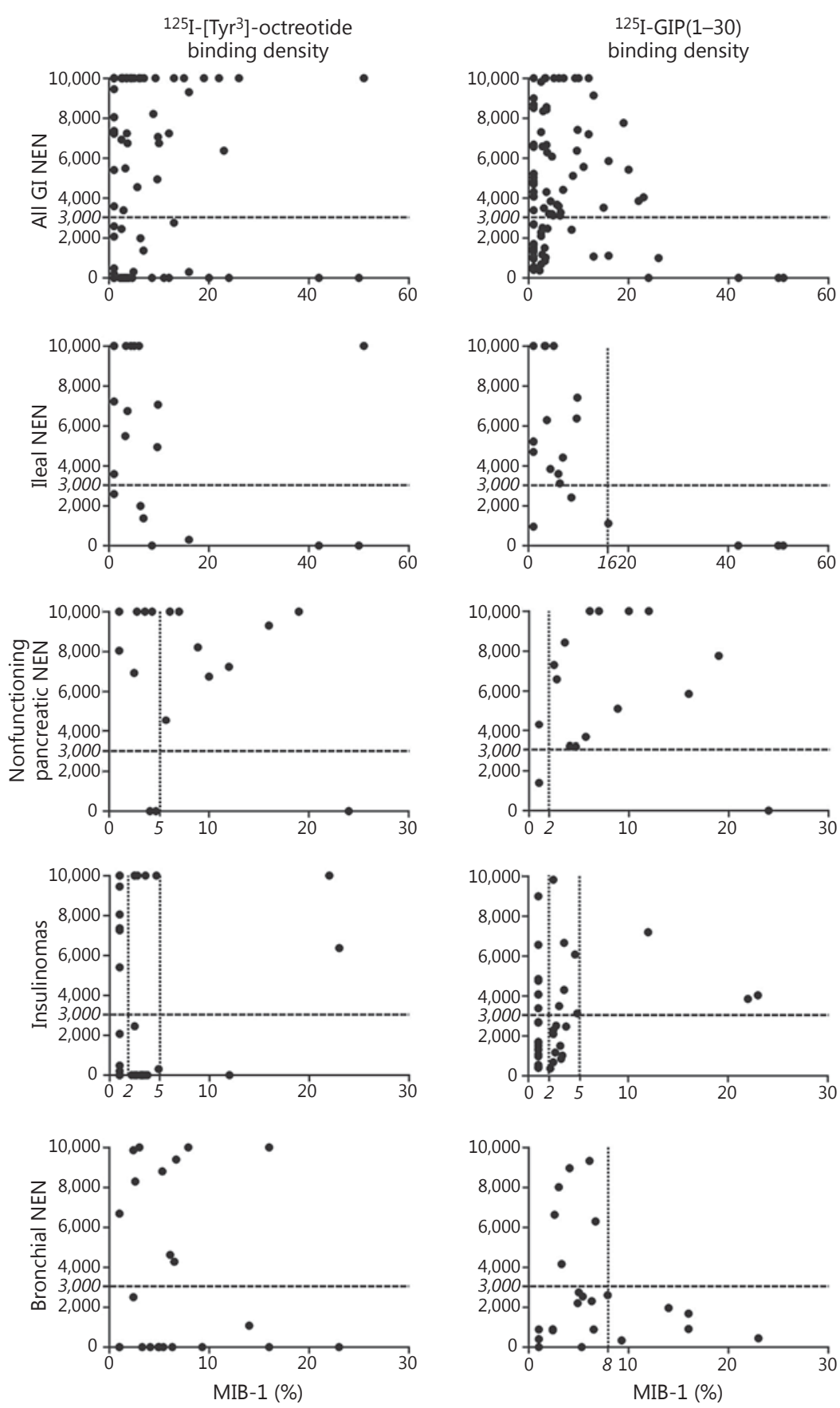

\section{In vitro Somatostatin Receptor and GIP Receptor}

Autoradiography

In vitro autoradiography for somatostatin and GIP receptors was carried out as described previously $[17,27]$. Briefly, 20- $\mu \mathrm{m}-$ thick cryostat sections of tumor tissues were incubated with either ${ }^{125}$ I-[Tyr3]-octreotide (Anawa, Wangen, Switzerland) (for somatostatin receptors) or ${ }^{125} \mathrm{I}-\mathrm{GIP}(1-30)$ (Anawa) (for GIP receptors) for $2 \mathrm{~h}$ at room temperature. Nonspecific binding was assessed by incubating serial tissue sections with the radioligand in the presence of excess cold peptide. Then, the slides were exposed to Kodak films Biomax $\mathrm{MR}^{\circledR}$ for 7 days at $4^{\circ} \mathrm{C}$. Radioligand binding to the tumors was analyzed in correlation with morphology using corresponding hematoxylin and eosin-stained tissue sections. Radioligand binding densities were measured in $\mathrm{dpm} / \mathrm{mg}$ tissue using 
Table 1. sst2 and GIP receptor incidences and mean densities according to MIB-1 levels and tumor stage in different NEN subgroups

\begin{tabular}{ll} 
sst2 receptors & \\
incidence & density \\
\cline { 2 - 3 } & mean $^{1} \pm$ SEM $\quad$ low $^{2}$ moderate $^{2}$ high $^{2}$
\end{tabular}

GIP receptors

incidence density

mean $^{1} \pm$ SEM low $^{2}$ moderate $^{2}$ high $^{2}$

\section{All gastrointestinal NEN}

$\begin{array}{lrllll}\text { MIB- } \leq 2 \% & 22 / 32(69 \%) & 7,352 \pm 725 & 2 & 2 & 18 \\ \text { MIB-1 } 2-20 \% & 37 / 52(71 \%) & 7,487 \pm 534 & 2 & 4 & 31 \\ \text { MIB-1 }>20 \% & 4 / 7(57 \%) & 9,092 \pm 908 & 0 & 0 & \\ \text { All } & 63 / 91(69 \%) & 7,541 \pm 406 & 4 & 6 & 53 \\ \text { N0 M0 } & 9 / 25(36 \%) & 6,197 \pm 1,346 & 2 & 1 & \\ \text { N+ and/or M+ } & 33 / 39(85 \%) & 7,824 \pm 518 & 1 & 3 & 29\end{array}$

$\begin{array}{lr}2 & 18 \\ 4 & 3 \\ 0 & 53 \\ 6 & 5 \\ 1 & 29 \\ 3 & \end{array}$

$\begin{array}{rcc}18 & 31 / 31(100 \%) & 3,583 \pm 501 \\ 31 & 51 / 51(100 \%) & 5,299 \pm 442 \\ 4 & 3 / 7(43 \%) & 2,962 \pm 984 \\ 53 & 86 / 90(96 \%) & 4,579 \pm 335 \\ 6 & 24 / 24(100 \%) & 3,889 \pm 586 \\ 29 & 37 / 39(95 \%) & 5,726 \pm 521\end{array}$

16

38

$\begin{array}{rrr}3 & 10 & 38 \\ 1 & 0 & 2\end{array}$

$\begin{array}{rrr}1 & 0 & 2 \\ 11 & 19 & 56\end{array}$

$\begin{array}{lll}2 & 9 & 13\end{array}$

\section{Ileal NEN}

MIB- $1 \leq 2 \%$

MIB-1 2-20\%

$5 / 5(100 \%) \quad 6,678 \pm 1,560 \quad 0 \quad 1$

MIB- $1>20 \%$

$11 / 12(92 \%)$

$6,171 \pm 1,115 \quad 1 \quad 2$

$1 / 3(33 \%) \quad 10,000 \quad 0 \quad 0$

All

$17 / 20(85 \%)$

$6,545 \pm 855 \quad 1 \quad 3$

$\begin{array}{rrlllr}4 & 5 / 5(100 \%) & 5,216 \pm 1,437 & 1 & 0 & 4 \\ 8 & 12 / 12(100 \%) & 5,714 \pm 902 & 0 & 2 & 10 \\ 1 & 0 / 3(0 \%) & & 0 & 0 & 0 \\ 13 & 17 / 20(85 \%) & 5,567 \pm 741 & 1 & 2 & 14 \\ & - & & & & \\ 9 & 13 / 15(87 \%) & 5,751 \pm 682 & 1 & 2 & 10\end{array}$

$\mathrm{N}+$ and/or $\mathrm{M}+\quad 13 / 15(87 \%)$

Nonfunctioning pancreatic NEN

MIB- $1 \leq 2 \%$ $2 / 2(100 \%)$

$5,872 \pm 996 \quad 1 \quad 3$

$12 / 14(86 \%) \quad 8,024 \pm 976$

$\begin{array}{lll}9,024 \pm 976 & 0 & 0\end{array}$

\section{2}

12

$0 / 1(0 \%)$

MIB-1 > 20\%

All

$14 / 17(82 \%)$

$8,645 \pm 464$

$3 / 4(75 \%) \quad 9,080 \pm 920$

$\begin{array}{ll}0 & 0\end{array}$

0

N0 M0

$10 / 11(91 \%) \quad 8,448 \pm 603$

$\begin{array}{ll}0 & 0 \\ 0 & 0\end{array}$

14

14
3

3
10

$\begin{array}{rcl}2 & 2 / 2(100 \%) & 2,849 \pm 1,456 \\ 12 & 13 / 13(100 \%) & 7,011 \pm 732 \\ 0 & 0 / 1(0 \%) & \\ 14 & 15 / 16(94 \%) & 6,456 \pm 749 \\ 3 & 3 / 3(100 \%) & 5,835 \pm 2,107 \\ 10 & 11 / 11(100 \%) & 6,680 \pm 900\end{array}$

$\begin{array}{ll}0 & 1 \\ 0 & 0 \\ 0 & 0 \\ 0 & 1 \\ 0 & 0 \\ 0 & 1\end{array}$

$\mathrm{N}+$ and/or $\mathrm{M}+$

00

\begin{tabular}{|c|c|c|c|c|c|c|c|c|c|c|}
\hline \multicolumn{11}{|l|}{ Insulinomas } \\
\hline MIB-1 $\leq 2 \%$ & $11 / 21(52 \%)$ & $6,390 \pm 1,152$ & 2 & 1 & 8 & $21 / 21(100 \%)$ & $2,570 \pm 501$ & 6 & 8 & 7 \\
\hline MIB-1 2-20\% & 7/17 (41\%) & $7,537 \pm 1,607$ & 1 & 1 & 5 & $17 / 17(100 \%)$ & $3,274 \pm 653$ & 3 & 7 & 7 \\
\hline MIB-1 > $20 \%$ & $2 / 2(100 \%)$ & $8,184 \pm 1,816$ & 0 & 0 & 2 & $2 / 2(100 \%)$ & $3,946 \pm 89$ & 0 & 0 & 2 \\
\hline All & $20 / 40(50 \%)$ & $6,971 \pm 843$ & 3 & 2 & 15 & $40 / 40(100 \%)$ & $2,938 \pm 383$ & 9 & 15 & 16 \\
\hline N0 M0 & $5 / 20(25 \%)$ & $4,258 \pm 2,007$ & 2 & 1 & 2 & $20 / 20(100 \%)$ & $3,363 \pm 571$ & 2 & 9 & 9 \\
\hline $\mathrm{N}+$ and/or $\mathrm{M}+$ & $3 / 4(75 \%)$ & $9,121 \pm 879$ & 0 & 0 & 3 & $4 / 4(100 \%)$ & $4,387 \pm 1,497$ & 1 & 0 & 3 \\
\hline \multicolumn{11}{|l|}{ Gastrinomas } \\
\hline MIB-1 $\leq 2 \%$ & $3 / 3(100 \%)$ & $10,000 \pm 0$ & 0 & 0 & 3 & $3 / 3(100 \%)$ & $6,739 \pm 1,006$ & 0 & 0 & 3 \\
\hline MIB-1 2-20\% & $3 / 3(100 \%)$ & $9,080 \pm 920$ & 0 & 0 & 3 & $3 / 3(100 \%)$ & $7,360 \pm 1,962$ & 0 & 0 & 3 \\
\hline MIB-1 > 20\% & - & & & & & - & & & & \\
\hline All & $6 / 6(100 \%)$ & $9,540 \pm 460$ & 0 & 0 & 6 & $6 / 6(100 \%)$ & $7,050 \pm 996$ & 0 & 0 & 6 \\
\hline N0 M0 & $1 / 1(100 \%)$ & 7,239 & 0 & 0 & 1 & $1 / 1(100 \%)$ & 8,556 & 0 & 0 & 1 \\
\hline $\mathrm{N}+$ and/or $\mathrm{M}+$ & $3 / 3(100 \%)$ & $10,000 \pm 0$ & 0 & 0 & 3 & $3 / 3(100 \%)$ & $6,237 \pm 1,456$ & 0 & 0 & 3 \\
\hline \multicolumn{11}{|l|}{ Glucagonomas } \\
\hline MIB- $1 \leq 2 \%$ & $1 / 1(100 \%)$ & 10,000 & 0 & 0 & 1 & $1 / 1(100 \%)$ & 8,676 & 0 & 0 & 1 \\
\hline MIB-1 2-20\% & $1 / 2(50 \%)$ & 2,764 & 0 & 1 & 0 & $2 / 2(100 \%)$ & $3,318 \pm 2,246$ & 0 & 1 & 1 \\
\hline MIB-1 > 20\% & - & & & & & - & & & & \\
\hline All & $2 / 3(67 \%)$ & $6,382 \pm 3,618$ & 0 & 1 & 1 & $3 / 3(100 \%)$ & $5,104 \pm 2,207$ & 0 & 1 & 2 \\
\hline N0 M0 & - & & & & & - & & & & \\
\hline $\mathrm{N}+$ and/or $\mathrm{M}+$ & $1 / 2(50 \%)$ & 10,000 & 0 & 0 & 1 & $2 / 2(100 \%)$ & $7,120 \pm 1,556$ & 0 & 0 & 2 \\
\hline \multicolumn{11}{|l|}{ VIPomas } \\
\hline MIB- $1 \leq 2 \%$ & - & & & & & - & & & & \\
\hline MIB-1 2-20\% & $3 / 4(75 \%)$ & $7,759 \pm 2,205$ & 0 & 0 & 3 & $4 / 4(100 \%)$ & $6,549 \pm 1,353$ & 0 & 0 & 4 \\
\hline MIB-1 > 20\% & $1 / 1(100 \%)$ & 10,000 & 0 & 0 & 1 & $1 / 1(100 \%)$ & 994 & 1 & 0 & 0 \\
\hline All & $4 / 5(80 \%)$ & $8,347 \pm 1,654$ & 0 & 0 & 4 & $5 / 5(100 \%)$ & $5,438 \pm 1,527$ & 1 & 0 & 4 \\
\hline N0 M0 & - & & & & & - & & & & \\
\hline $\mathrm{N}+$ and/or $\mathrm{M}+$ & $3 / 4(75 \%)$ & $10,000 \pm 0$ & 0 & 0 & 3 & $4 / 4(100 \%)$ & $4,708 \pm 1,732$ & 1 & 0 & 3 \\
\hline
\end{tabular}


Table 1 (continued)

\begin{tabular}{|c|c|c|c|c|c|c|c|c|c|c|}
\hline & \multicolumn{5}{|l|}{ sst2 receptors } & \multicolumn{5}{|l|}{ GIP receptors } \\
\hline & incidence & mean $^{1} \pm$ SEM & low $^{2}$ & moderate $^{2}$ & high $^{2}$ & incidence & $\operatorname{mean}^{1} \pm \mathrm{SEM}$ & $\operatorname{low}^{2}$ & moderate $^{2}$ & high $^{2}$ \\
\hline \multicolumn{11}{|c|}{ Bronchopulmonary NEN } \\
\hline MIB- $1 \leq 2 \%$ & $1 / 3(33 \%)$ & 6,686 & 0 & 0 & 1 & $2 / 3(67 \%)$ & $649 \pm 243$ & 2 & 0 & 0 \\
\hline MIB-1 $2-20 \%$ & $11 / 19(58 \%)$ & $7,168 \pm 1,018$ & 0 & 2 & 9 & $18 / 19(95 \%)$ & $3,517 \pm 702$ & 5 & 7 & 6 \\
\hline All & $12 / 23(52 \%)$ & $7,128 \pm 930$ & 0 & 2 & 10 & $21 / 23(91 \%)$ & $3,097 \pm 642$ & 8 & 7 & 6 \\
\hline No M0 & $3 / 7(43 \%)$ & $6,936 \pm 2,268$ & 0 & 0 & 3 & $7 / 7(100 \%)$ & $4,056 \pm 1,037$ & 2 & 1 & 4 \\
\hline $\mathrm{N}+$ and/or $\mathrm{M}+$ & $3 / 4(75 \%)$ & $8,452 \pm 934$ & 0 & 1 & 2 & $3 / 4(75 \%)$ & $742 \pm 150$ & 3 & 0 & 0 \\
\hline
\end{tabular}

${ }^{1}$ Only receptor-positive cases. ${ }^{2}$ Low receptor density: <1,000 dpm/mg; moderate receptor density: 1,000-3,000 dpm/mg; high receptor density: $>3,000 \mathrm{dpm} / \mathrm{mg}$.

Table 2. Individual MIB-1 values and sst 2 and GIP receptor density levels in high-grade NEN with MIB-1 $>20 \%$ and metastases of NEN

\begin{tabular}{llrc}
\hline Tumor type & MIB-1, & \multicolumn{2}{l}{ Density, dpm/mg } \\
\cline { 3 - 5 } & $\%$ & sst2 & GIP receptor \\
\hline High-grade NEN & & & \\
Ileal NEN & 42 & 0 & 0 \\
& 50 & 0 & 0 \\
& 51 & 10,000 & 0 \\
Nonfunctioning pancreatic NEN & 24 & 0 & 0 \\
Insulinoma & 22 & 10,000 & 3,857 \\
& 23 & 6,368 & 4,035 \\
VIPoma & 26 & 10,000 & 994 \\
Bronchial NEN & 23 & 0 & 442 \\
\hline NEN metastases & & & \\
Ileal NEN (liver) & 1 & 7,220 & 956 \\
Nonfunctioning pancreatic & & & \\
$\quad$ NEN (liver) & 16 & 9,306 & 5,854 \\
Insulinoma (lymph node) & 12 & 0 & 7,198 \\
VIPoma (liver) & 13 & 10,000 & 9,141 \\
Bronchial NEN (lymph node) & 6 & 0 & 2,300 \\
\hline
\end{tabular}

Organ in parentheses indicates site of metastasis.

tissue standards containing known amounts of isotope and crosscalibrated to tissue-equivalent ligand concentrations [28, 29] as well as a computer-assisted imaging system (Interfocus, Mering, Germany). Due to saturation of radioligand binding to receptor binding sites in the tissues, the maximum binding density value measurable with the method was $10,000 \mathrm{dpm} / \mathrm{mg}$. Radioligand binding densities $<1,000 \mathrm{dpm} / \mathrm{mg}$ tumor tissue were considered to correspond to low tumoral receptor levels, densities between 1,000 and $3,000 \mathrm{dpm} / \mathrm{mg}$ to moderate receptor levels, and densities $>3,000 \mathrm{dpm} / \mathrm{mg}$ to high receptor levels [17]. In the case of somatostatin receptors, density levels above $3,000 \mathrm{dpm} / \mathrm{mg}$ were expected to be high enough for positive somatostatin receptor imaging, based on previous comparative data $[24,30,31]$.

\section{MIB-1 Immunohistochemistry}

The immunohistochemical Ki-67 proliferative index of NEN was assessed using an MIB-1 antibody (Dako, Glostrup, Denmark). Frozen tissue sections of the same tumor samples subjected to in vitro receptor autoradiography were fixed in acetone and postfixed in $4 \%$ formalin. The primary antibody was applied at a 1:50 concentration. The secondary antibody was a biotinylated goat anti-mouse immunoglobulin (1:300; Dako). Antibody binding was visualized using the ABComplex Elite (Vector Laboratories, Burlingame, Calif., USA). Staining was carried out with $3,3^{\prime}$-diaminobenzidine, and counterstaining with hemalum. In each case, the percentage of MIB-1-positive tumor cells was assessed by counting 2,000 tumor cells.

\section{Statistical Evaluation}

Linear regression analysis and the Spearman's rank correlation coefficient $\mathrm{r}^{2}$ were used to correlate the MIB-1 proliferative index with autoradiographic receptor density levels, and the $\mathrm{p}$ value was calculated using Student's t test. Fisher's exact test and Student's t test were applied to compare receptor incidences and densities between N0 M0 and N+/M+ tumors. $\mathrm{p} \leq 0.05$ was considered to be statistically significant.

\section{Results}

\section{Proliferative Index and Somatostatin and GIP \\ Receptor Expression in NEN}

The MIB-1 proliferative index as well as the somatostatin and GIP receptor density levels were assessed with immunohistochemistry and receptor autoradiog- 
raphy, respectively, in the same tumor specimen and were compared with each other. For somatostatin receptor autoradiography, the radioligand ${ }^{125} \mathrm{I}-[\mathrm{Tyr} 3]$ octreotide was used, which mainly recognizes the somatostatin receptor subtype 2 (sst2). The results are shown for each individual case in figure 1 and are summarized in table 1 . In addition, table 2 shows the individual results of all grade 3 tumors and of the metastases.

\section{Gastrointestinal NEN in General}

Looking at all NEN of gastrointestinal origin, tumors with an MIB-1 proliferative index $\leq 20 \%$ frequently showed a high expression of both sst 2 and GIP receptors, with a lower incidence but higher mean density of the former. The incidences amounted to around $70 \%$ for sst 2 and reached $100 \%$ for GIP receptors. Moreover, both sst2 and GIP receptors were expressed at high density levels (i.e. $>3,000 \mathrm{dpm} / \mathrm{mg}$ tumor tissue, expected to be high

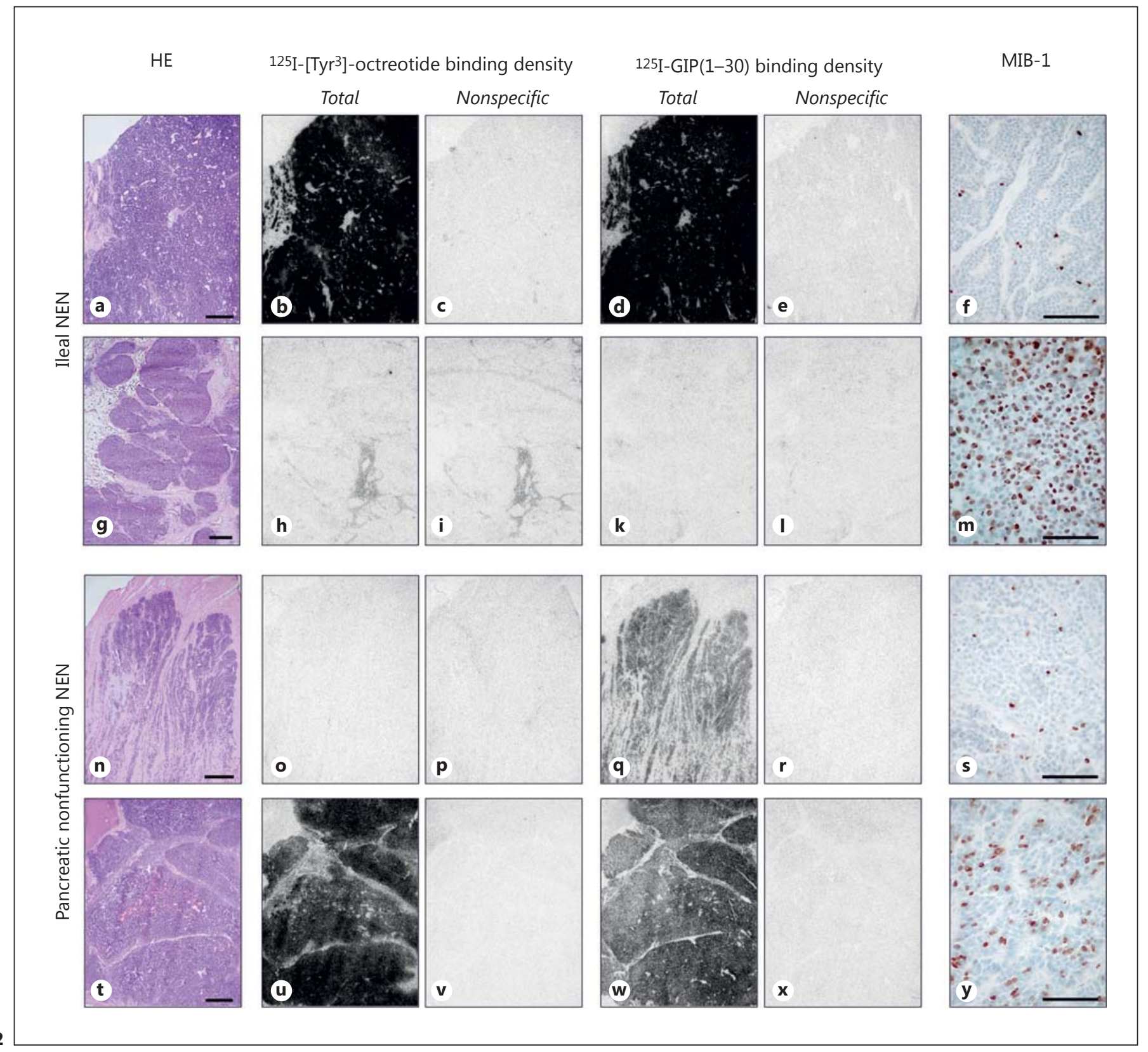

(For legend see next page.) 
enough for clinical applications) in over half of the tumors with MIB- 1 positivity $<2 \%$ and 59 and $74 \%$, respectively, of cases with an MIB-1 proliferative index between 2 and $20 \%$.

In 7 gastrointestinal NEN, the MIB-1 proliferative index exceeded $20 \%$. Compared with NEN with less proliferation, these tumors generally showed lower receptor incidences ( $57 \%$ for sst2, $43 \%$ for GIP receptors). Remarkably, receptor density levels were still high in a subset of these tumors (table 2). This was particularly the case for sst2, which was expressed at extremely high levels in all 4 sst2-positive tumors. Conversely, GIP receptor levels were markedly reduced with increasing proliferative rates. Specifically, in NEN with MIB-1 $>23 \%$, GIP receptors were expressed at low levels (i.e. $<1,000 \mathrm{dpm} / \mathrm{mg}$ tumor tissue) or were completely absent.

\section{Ileal NEN}

Separate analyses of individual subgroups of gastrointestinal NEN were also performed. Ileal tumors were thus found to generally express both sst2 and GIP receptors in high incidence and high density. However, the GIP receptor density levels progressively declined with increasing MIB-1 positivity, which was statistically significant $\left(\mathrm{r}^{2}=\right.$ $0.276 ; \mathrm{p}=0.017$ ). In particular, all tumors with an MIB-1 positivity rate $\geq 16 \%$ showed low densities of or were completely negative for GIP receptors. In contrast, 1 of the 4 ileal NEN with MIB-1 $\geq 16 \%$ still exhibited a very high sst2 density.

Fig. 2. Comparison of ${ }^{125} \mathrm{I}-[\mathrm{T} y \mathrm{r} 3]$-octreotide and ${ }^{125} \mathrm{I}-\mathrm{GIP}(1-30)$ binding autoradiography with MIB-1 immunohistochemistry in two different ileal NEN (rows 1 and 2) and two nonfunctioning pancreatic NEN (rows 3 and 4). The first 5 images in each row show serial tissue sections of the same tumor specimen at the same scanning magnification (bars $=1 \mathrm{~mm}$ ); the last image in the row shows MIB-1 immunohistochemistry in the same specimen at higher magnification (bars $=0.1 \mathrm{~mm}$ ). Column 1: HE staining. Columns 2 and 3: ${ }^{125} \mathrm{I}$-[Tyr3]-octreotide autoradiography, where column 2 shows total ${ }^{125} \mathrm{I}$-[Tyr3]-octreotide binding and column 3 nonspecific ${ }^{125} \mathrm{I}$-[Tyr3]-octreotide binding in the presence of excess cold octreotide. Columns 4 and 5: ${ }^{125} \mathrm{I}-\mathrm{GIP}(1-30)$ autoradiography, where column 4 shows total ${ }^{125}$ I-GIP(1-30) binding and column 5 nonspecific ${ }^{125} \mathrm{I}-\mathrm{GIP}(1-30)$ binding in the presence of excess cold GIP(1-30). Column 6: MIB-1 immunohistochemistry. a-f Ileal NEN with high sst 2 and GIP receptor expression and low proliferation. a HE staining showing the tumor tissue. b Strong total ${ }^{125} \mathrm{I}$-[Tyr3]-octreotide binding to the entire tumor sample. c Complete displacement of ${ }^{125} \mathrm{I}$-[Tyr3]-octreotide by cold octreotide provides evidence of specificity of ${ }^{125} \mathrm{I}$-[Tyr3]-octreotide bind-
Two representative ileal NEN are depicted in figure 2. The tumor in the first row shows a low MIB-1 expression (3.4\%) together with a strong specific binding of the radioligands ${ }^{125} \mathrm{I}$-[Tyr3]-octreotide and ${ }^{125} \mathrm{I}-\mathrm{GIP}(1-30)$, corresponding to a high number of sst2 and GIP receptor binding sites, respectively. In contrast, the example in the second row is characterized by a high MIB-1 positivity rate of $24 \%$, but no specific binding of ${ }^{125} \mathrm{I}$-[Tyr3]-octreotide or ${ }^{125} \mathrm{I}-\mathrm{GIP}(1-30)$; there are no detectable sst2 or GIP receptors in this tumor.

\section{Nonfunctioning Pancreatic NEN}

Also in nonfunctioning pancreatic NEN, tumors with an MIB-1 proliferative index $\leq 20 \%$ showed high expression of both sst 2 and GIP receptors, whereas a single case with MIB-1 $>20 \%$ was completely receptor negative. Receptor density levels were extremely high, even higher than in ileal NEN. There was an insignificant trend for an increase in receptor density levels with increasing MIB-1. In fact, in tumors with an MIB- 1 proliferative index $\geq 2 \%$, the GIP receptor density was always high. The same holds true for sst2 in tumors with MIB-1 $>5 \%$. This is illustrated in figure 2. In the example in the third row with an MIB-1 positivity rate of $4 \%$, there are no detectable somatostatin receptors and GIP receptor levels just above 3,000 $\mathrm{dpm} / \mathrm{mg}$, while the tumor in the fourth row with an MIB1 positivity rate of $16 \%$ exhibits very high levels of both receptors. ing to sst2; no nonspecific ${ }^{125} \mathrm{I}$-[Tyr3]-octreotide binding. $\mathbf{d}$ Similarly, strong total ${ }^{125} \mathrm{I}-\mathrm{GIP}(1-30)$ binding to the entire tumor sample. e Complete displacement of ${ }^{125} \mathrm{I}-\mathrm{GIP}(1-30)$ by cold GIP proves specificity of ${ }^{125} \mathrm{I}-\mathrm{GIP}(1-30)$ binding. $\mathbf{f} 3.4 \%$ of tumor cells stain for MIB-1. g-m Ileal NEN without sst2 or GIP receptor expression, with high proliferation. g HE staining showing tumor tissue. $\mathbf{h}$, i No specific ${ }^{125}$ I-[Tyr3]-octreotide binding to the tumor. $\mathbf{k}$, I No specific ${ }^{125}$ I-GIP(1-30) binding to the tumor. $\mathbf{m} 24 \%$ of tumor cells are positive for MIB-1. $\mathbf{n}-\mathbf{s}$ Nonfunctioning pancreatic NEN without sst 2 expression, with marginally elevated GIP receptor levels and low proliferation. $\mathbf{n}$ HE staining showing tumor tissue. o, p No specific ${ }^{125}$ I-[Tyr3]-octreotide binding to the tumor. $\mathbf{q}, \mathbf{r}$ Weak specific ${ }^{125}$ I-GIP(1-30) binding to the tumor. $\mathbf{s} 4.1 \%$ of tumor cells are MIB-1 positive. t-x Nonfunctioning pancreatic NEN with very high sst 2 and GIP receptor expression and high proliferation. $\mathbf{t} \mathrm{HE}$ staining showing tumor tissue. $\mathbf{u}, \mathbf{v}$ Very strong specific binding of ${ }^{125} \mathrm{I}$-[Tyr3]-octreotide. $\mathbf{w}, \mathbf{x}$ Very strong specific binding of ${ }^{125} \mathrm{I}-\mathrm{GIP}(1-30)$, markedly stronger than in $\mathbf{q} . \mathbf{y} 16 \%$ of tumor cells stain for MIB-1. 
Fig. 3. Comparison of binding site levels (dpm/mg tissue) of sst2 ( $\mathrm{x}$-axis) and GIP receptors (y-axis) in individual cases. Black points: cases with comparable sst 2 and GIP receptor density levels; red points: cases with high sst 2 but low GIP receptor density levels; blue points: cases with high GIP receptor but low sst 2 density levels. Particularly insulinomas often show disparate sst2 and GIP receptor levels.

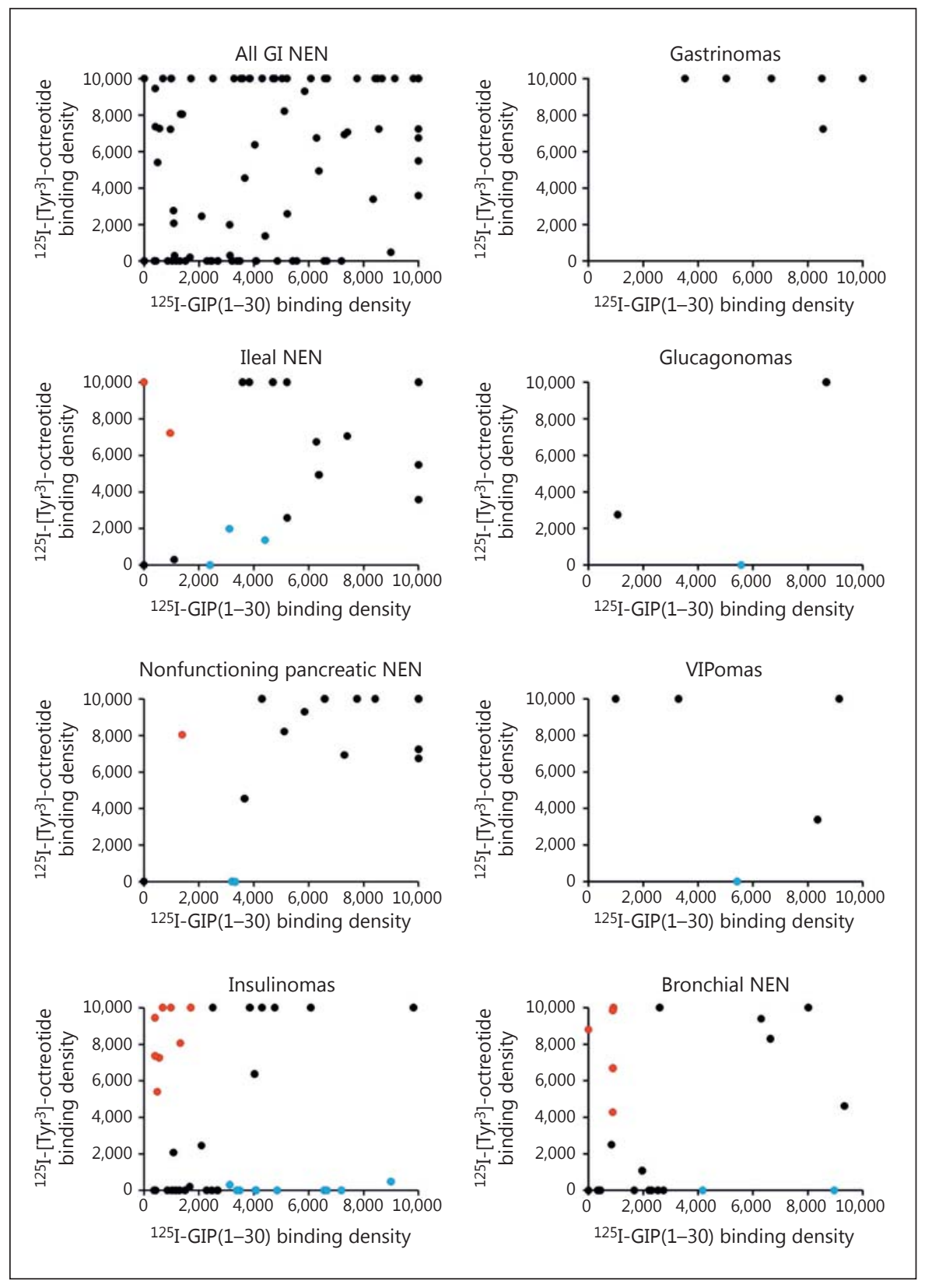

\section{Insulinomas}

In general, insulinomas with an MIB-1 proliferative index $<20 \%$ expressed sst 2 at moderate incidence rates with very high mean densities, and GIP receptors at $100 \%$ incidence rates with moderate mean densities. Many insulinomas exhibited a proliferative index between 2 and $5 \%$. In this subset of tumors, sst2 and GIP receptor expression patterns differed even more markedly. Most cases were either very strongly positive or completely negative for sst2. In contrast, there was a continuous increase in GIP receptor density levels with increasing MIB-1 positivity rate. If one outlying case (GIP receptor density 9,818 dpm/mg, MIB-1 2.5\%) was excluded, this increase was even statistically significant $\left(r^{2}=0.3663 ; p=0.017\right)$. All insulinomas with MIB- $1 \geq 5 \%$ showed high GIP receptor levels, including 2 cases with MIB- $1>20 \%$.

Other Functioning Pancreatic and Duodenal NEN

Only a few cases of other functioning NEN, including gastrinomas, glucagonomas, and VIPomas, were avail- 


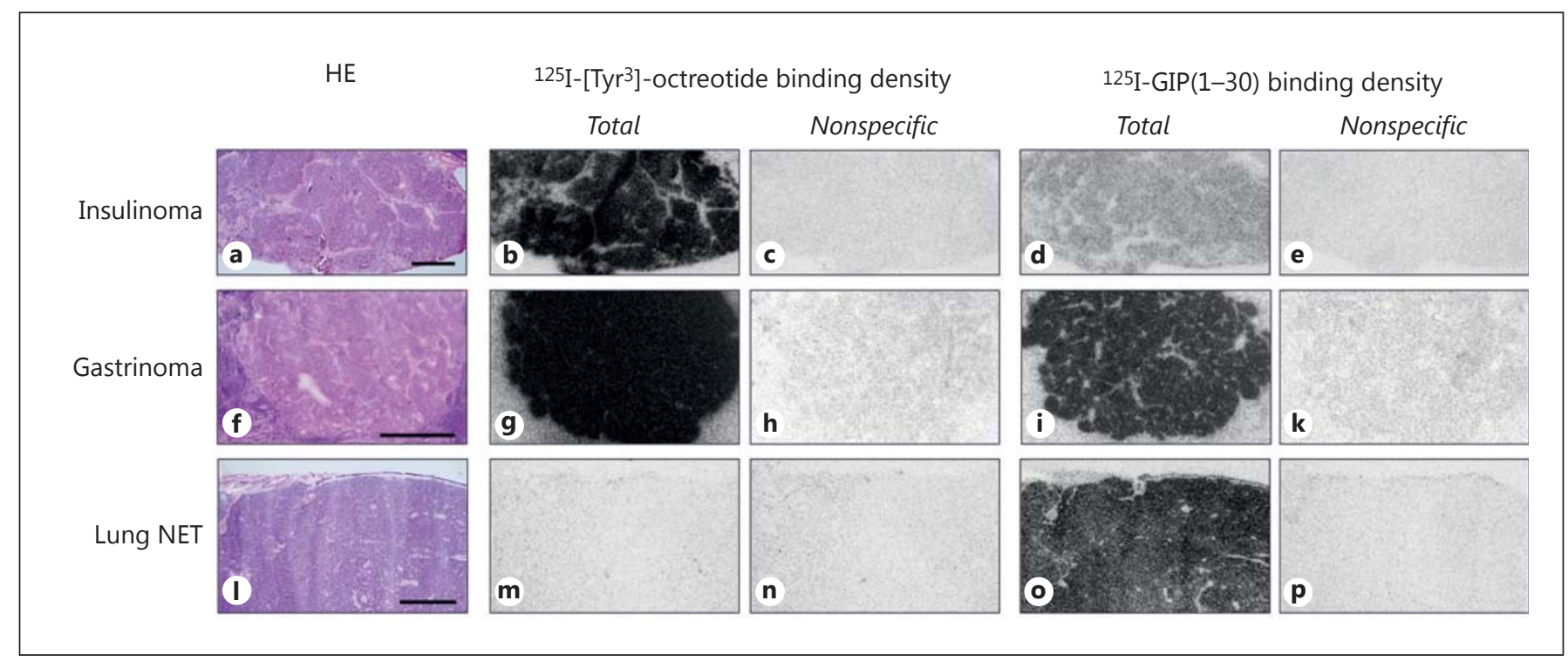

Fig. 4. Comparison of ${ }^{125} \mathrm{I}-[\mathrm{T} y \mathrm{r} 3]$-octreotide with ${ }^{125} \mathrm{I}-\mathrm{GIP}(1-30)$ autoradiography on serial tissue sections of an insulinoma (first row), a gastrinoma (middle row), and a bronchial NEN (last row). Column 1: HE-stained tissue sections (bars $=1 \mathrm{~mm}$ ). Columns 2 and 3: ${ }^{125} \mathrm{I}$-[Tyr3]-octreotide autoradiography, where column 2 shows total ${ }^{125}$ I-[Tyr3]-octreotide binding and column 3 nonspecific ${ }^{125} \mathrm{I}$-[Tyr3]-octreotide binding in the presence of excess cold octreotide. Columns 4 and 5: ${ }^{125} \mathrm{I}-\mathrm{GIP}(1-30)$ autoradiography, where column 4 shows total ${ }^{125} \mathrm{I}-\mathrm{GIP}(1-30)$ binding and column 5 nonspecific ${ }^{125} \mathrm{I}-\mathrm{GIP}(1-30)$ binding in the presence of excess cold
GIP(1-30). a-e Example of an insulinoma with a high sst2 but low GIP receptor expression: the tumor (a) exhibits strong ${ }^{125}$ I-[Tyr3]octreotide binding $(\mathbf{b}, \mathbf{c})$ but only little specific ${ }^{125} \mathrm{I}-\mathrm{GIP}(1-30)$ binding (d, e). f-k Example of a gastrinoma with a high expression of both sst2 and GIP receptors: the tumor (f) shows strong specific binding of both ${ }^{125} \mathrm{I}$-[Tyr3]-octreotide $(\mathbf{g}, \mathbf{h})$ and ${ }^{125} \mathrm{I}$ GIP(1-30) (i, k). I-p Example of a bronchial NEN with a high GIP receptor expression but no sst 2 expression. In the tumor (I), there is no detectable ${ }^{125} \mathrm{I}$-[Tyr3]-octreotide binding $(\mathbf{m}, \mathbf{n})$ but strong ${ }^{125}$ I-GIP(1-30) binding $(\mathbf{o}, \mathbf{p})$. NET = Neuroendocrine tumor. able for examination. All 6 gastrinomas were strongly positive for both sst2 and GIP receptors, irrespective of the MIB-1 proliferative index. Glucagonomas showed high sst 2 and GIP receptor densities in the case of MIB-1 $<2 \%$, but lower receptor levels when the MIB-1 positivity rate ranged between 2 and 20\%. Conversely, VIPomas with an MIB-1 proliferative index between 2 and $20 \%$ expressed both sst 2 and GIP receptors at high levels. A single VIPoma with MIB-1 >20\% exhibited a very high sst2, but a low GIP receptor density.

\section{Bronchopulmonary NEN}

Bronchopulmonary NEN expressed sst 2 at lower incidence rates than the majority of gastrointestinal NEN, but often in high densities. Conversely, they expressed GIP receptors at high incidence rates, but in more variable densities. In fact, GIP receptor density levels progressively declined with increasing MIB-1 positivity, which was statistically significant for the cases with MIB- $1>2.5 \%\left(\mathrm{r}^{2}=\right.$ $0.2656 ; \mathrm{p}=0.007$ ). In bronchial NEN with MIB- $1 \geq 8 \%$, GIP receptor density levels were always moderate or low.

\section{Tumor Stage and Somatostatin and GIP Receptor Expression in NEN}

In 75 of the 114 NEN (66\%), data on TNM stage were available. For further analysis, these cases were subdivided into two biologically and clinically distinct groups, namely those without evidence of metastasis (N0 M0) and those with nodal and/or distant metastases $(\mathrm{N}+/ \mathrm{M}+)$. Results are summarized in table 1.

In gastrointestinal NEN, the incidences of both sst2 and GIP receptors were generally high in metastasized cases, except for glucagonomas, where the sst2 incidence amounted to only $50 \%$. When comparing $\mathrm{N}+/ \mathrm{M}+$ tumors with N0 M0 tumors, receptor incidences were either equally high or higher, but never lower in the former. This was particularly the case for the sst 2 incidences in nonfunctioning pancreatic NEN and insulinomas, which were prominently higher in the metastasized cases. Likewise, mean receptor density levels were almost always similarly high or higher in $\mathrm{N}+/ \mathrm{M}+$ compared with N0 M0 tumors, the only exception being gastrinomas where GIP receptor densities were slightly reduced in metastasized cases. 
In bronchial NEN, sst 2 incidence was moderate in N0 M0 tumors and higher in $\mathrm{N}+\mathrm{M}+$ cases, while the sst2 density levels were high in both tumor groups. In contrast, GIP receptor density levels were fairly high in nonmetastasized cases, but showed a reduction in $\mathrm{N}+/ \mathrm{M}+\mathrm{tu}-$ mors.

However, differences in receptor incidences and density levels between N0/M0 and $\mathrm{N}+/ \mathrm{M}+$ tumors did not reach statistical significance in any investigated tumor subgroup.

\section{Comparison of sst2 and GIP Receptor Levels in NEN}

The binding site density levels of sst 2 and GIP receptors were also compared with each other in the individual tumors. The data are shown in figure 3 and are illustrated with typical examples in figure 4 .

In ileal NEN, the majority of the cases expressed sst 2 and GIP receptors at comparable levels: both receptors were present in similarly high or low density or were completely negative in the same tumor specimen. In only 2 tumors (marked in red in fig. 3) were sst2 levels markedly higher than GIP receptor levels, while 3 cases (marked in blue in fig. 3) showed a considerably stronger GIP receptor than sst 2 expression.

Likewise, in nonfunctioning pancreatic NEN, most cases expressed both sst 2 and GIP receptors at high levels. Only 2 tumors showed a considerably stronger GIP receptor than sst 2 expression, and the reverse was seen in a third tumor.

Conversely, in insulinomas, the sst 2 and GIP receptor expressions were often not congruent. Many of the cases with high sst2 density levels expressed low amounts of GIP receptors (red in fig. 3 ). This is also illustrated with a typical example in figure 4 (first row). On the other hand, many tumors virtually negative for sst 2 showed moderate or high GIP receptor density levels (blue in fig. 3).

Most gastrinomas, glucagonomas, and VIPomas expressed sst 2 and GIP receptors in comparable density. One of these cases, a gastrinoma, is depicted in figure 4 (middle row). Only single cases (one glucagonoma and one gastrinoma) showed high GIP receptor levels in the absence of sst 2 expression.

Of the investigated bronchopulmonary NEN, 5 cases with only low or no GIP receptor expression showed high to very high sst 2 levels. Conversely, most cases completely negative for sst 2 expressed GIP receptors in low to moderate density. One such case is shown in figure 4 (last row).

\section{Discussion}

In the classification of gastrointestinal NEN, emphasis has been put on a simple and uniform grading and staging system in recent times as the basis for prognostication, standardized therapy, and clinical studies. Indeed, tumor grade and stage correlate very well with biologic behavior. At the same time, it becomes apparent that peptide hormone receptors like somatostatin receptors, crucial molecular targets in NEN, exhibit a differential expression in these tumors which does not uniformly match with grade, stage, or the proliferative index. In the present study, this was for the first time systematically analyzed for sst 2 and GIP receptors in a large selection of gastrointestinal and bronchopulmonary NEN. In summary, a number of possible peptide receptor expression patterns were identified in various NEN subgroups. These patterns differed depending on tumor type and site of tumor origin and also correlated partially with the MIB-1 index. Such sst 2 and GIP receptor expression patterns are only emerging and will eventually have to be confirmed in a larger number of tumors.

First of all, the case collection reflects known typical features of peptide receptor expressions in NEN $[14,17]$. Both sst 2 and GIP receptors showed high incidences and densities (i.e. $>3,000 \mathrm{dpm} / \mathrm{mg}$ ) in gastrointestinal NEN, but lower expression levels in bronchopulmonary NEN. Furthermore, sst2 generally exhibited higher density levels than GIP receptors, while GIP receptors were expressed at higher incidence rates. Finally, the expression of both receptors was generally reduced in NEN with an MIB-1 proliferative index above $20 \%$ compared with tumors with lower proliferation. In grade 3 NEN, GIP receptors mostly showed no or low expression levels (density levels $<1,000 \mathrm{dpm} / \mathrm{mg}$ ), whereas the sst 2 expression was more often high.

Beyond that, peptide receptor levels were for the first time found to either increase or diminish progressively with growing proliferative rates. This was usually apparent in only a part of the proliferative spectrum and was frequently found for GIP receptors, while sst2 was more often expressed at random. Specifically, significant increases or trends for increases in GIP receptor levels with higher proliferative indices were present in grade 1 and 2 nonfunctioning pancreatic NEN and in insulinomas with MIB-1 positivity between 2 and 5\%. Conversely, a progressive decrease in the GIP receptor expression with higher proliferation was observed in ileal and bronchopulmonary NEN. In contrast, for sst2, only an insignifi- 
cant trend for increased levels with higher MIB-1 expression was found in grade 1 and 2 nonfunctioning pancreatic NEN.

Moreover, MIB-1 levels were observed in several NEN types above which peptide receptors showed consistently high or low densities. Of importance, these MIB-1 levels were not equivalent to those which defined tumor grade. They were exclusively seen for GIP receptors, but not for sst2. Specifically, GIP receptor levels were always high in insulinomas with MIB-1 $\geq 5 \%$, but consistently low in ileal NEN with MIB-1 $\geq 16 \%$ and in bronchial NEN with MIB- $1 \geq 8 \%$. While the absolute values of these various MIB-1 levels are only observations in one study population, they illustrate that tumor grade itself, defined by arbitrary MIB-1 cutoff levels and comprising a large MIB-1 spectrum, does not match with peptide receptor expression.

In the same context, sst2 expression levels in highgrade NEN with MIB- 1 fractions above $20 \%$ are noteworthy, even though only a small number of tumors could be analyzed due to the rarity of these cases [19]. In fact, it has been generally assumed that grade 3 NEN consistently show low somatostatin receptor expression levels. This concept has been supported by only little data derived mainly from somatostatin receptor imaging studies [19, 32], while it has been rarely investigated at the tissue level. The sst 2 incidence of $57 \%$ collected in vitro in tumor samples in the present study is well in agreement with published somatostatin receptor imaging results. However, the present study provides important additional information by measuring sst 2 density in vitro directly in tumor samples. Although sst2 densities were overall lower in grade 3 NEN compared with better differentiated tumors, they were still high in individual cases, as shown in table 2. Tumors with such strong receptor expression can be expected to be well suited for targeted imaging and therapy. Of note, the sst 2 expression in high-grade NEN was quite unpredictable in the present tumor cohort. In particular, it was independent of MIB-1 levels, tumoral hormone production, or site of tumor origin. It will clearly be worthwhile to analyze a larger number of grade 3 NEN for their somatostatin receptor expression at the tissue level.

Finally, sst 2 and GIP receptor expression patterns were found to differentially correlate with tumor stage. sst 2 incidences and densities were usually higher or, more rarely, similar in NEN with nodal and/or distant metastasis compared with tumors without evidence of metastasis. In contrast, GIP receptor levels were lower in metastasized versus nonmetastasized bronchopulmonary NEN, while they showed less difference in gastrointestinal NEN.
It was also interesting to compare in individual tumors the expression of sst 2 with that of GIP receptors. Indeed, sst2 and GIP receptor levels were either similar or strikingly disparate in a given case. This was rather tumor specific. In ileal NEN, nonfunctioning pancreatic NEN, and functioning pancreatic NEN other than insulinomas, expression levels of the two receptors were comparable in the majority of cases. Conversely, in insulinomas and a subset of bronchopulmonary NEN, there were often substantial differences in sst 2 and GIP receptor levels, with a high expression of one receptor and a low or no expression of the other.

In conclusion, although the expression of peptide receptors is a universal and highly typical feature of common gastrointestinal and bronchopulmonary NEN, it seems to differ between various tumor types and also to partially correlate with the proliferative index. The GIP receptor expression in NEN appears more often to follow a rule than the sst 2 expression. At present, it can only be speculated on its biological significance. GIP receptors can stimulate insulin secretion and possibly also tumor cell proliferation $[33,34]$. Accordingly, increased GIP receptor expression in insulinomas with low proliferative activity could promote insulin secretion. Likewise, in grade 1 and 2 nonfunctioning NEN it may stimulate tumor cell proliferation. On the other hand, a decrease in GIP receptor levels in ileal and bronchopulmonary NEN with growing proliferative activity may be reflective of tumor dedifferentiation. It appears that if GIP receptors play a significant biological role in NEN, this may vary between different tumor types.

As for clinical applications, the present study confirms that common NEN are good candidates for peptide receptor targeting for imaging and radiotherapeutic purposes based on the generally high peptide receptor incidences and densities (i.e. $>3,000 \mathrm{dpm} / \mathrm{mg}$ ). Of importance, the data underline that this accounts not only for cases with a proliferative index below $20 \%$, but also for a substantial subset of grade 3 tumors. Moreover, they highlight the potential of multireceptor targeting directed simultaneously at both sst 2 and GIP receptors as soon as GIP receptor targeting is clinically available. An additive targeting effect can be expected in ileal and nonfunctioning pancreatic NEN, which express both receptors concomitantly. Conversely, in insulinomas and bronchopulmonary NEN, where often only 1 of the 2 receptors is present in sufficient amounts, dual receptor targeting may be the method of choice, as the tumor would be missed by single receptor targeting. 
In terms of tumor testing, the study results emphasize the need to characterize each individual NEN for its peptide receptor expression when clinical applications are an option. The indications for in vitro tumor testing have been summarized previously [35]. At present, widespread in vitro testing is possible for sst 2 since a good immunohistochemical antibody is commercially available [24]. Indeed, in vitro testing of sst 2 in NEN is reasonable due to the unpredictable variations in the sst 2 expression. In particular, high-grade NEN need to be tested in order to identify those cases with strong sst 2 expression. We believe that in the era of personalized, targeted medicine, it is essential to gather as much information as possible on an individual tumor to be able to interdisciplinarily define the best ways of management and follow-up, especially if an inexpensive test such as sst 2 immunohistochemistry is available and alternative powerful therapeutic options are scarce.

\section{References}

-1 Jann H, Roll S, Couvelard A, Hentic O, Pavel M, Müller-Nordhorn J, Koch M, Röcken C, Rindi G, Ruszniewski P, Wiedenmann B, Pape UF: Neuroendocrine tumors of midgut and hindgut origin: tumor-node-metastasis classification determines clinical outcome. Cancer 2011;117:3332-3341.

-2 Strosberg JR, Cheema A, Weber J, Han G, Coppola D, Kvols LK: Prognostic validity of a novel American Joint Committee on Cancer Staging Classification for pancreatic neuroendocrine tumors. J Clin Oncol 2011;29:30443049.

3 Rindi G, Falconi M, Klersy C, Albarello L, Boninsegna L, Buchler MW, Capella C, Caplin M, Couvelard A, Doglioni C, Delle Fave G, Fischer L, Fusai G, de Herder WW, Jann H, Komminoth P, de Krijger RR, La Rosa S, Luong TV, Pape U, Perren A, Ruszniewski P, Scarpa A, Schmitt A, Solcia E, Wiedenmann B: TNM staging of neoplasms of the endocrine pancreas: results from a large international cohort study. J Natl Cancer Inst 2012; 104:764-777.

4 Arnold R, Chen YJ, Costa F, Falconi M, Gross D, Grossman AB, Hyrdel R, Kos-Kudła B, Salazar R, Plöckinger U; Mallorca Consensus Conference participants; European Neuroendocrine Tumor Society: ENETS Consensus Guidelines for the Standards of Care in Neuroendocrine Tumors: follow-up and documentation. Neuroendocrinology 2009;90: 227-233.

5 Binderup T, Knigge U, Loft A, Mortensen J, Pfeifer A, Federspiel B, Hansen CP, Højgaard L, Kjaer A: Functional imaging of neuroendocrine tumors: a head-to-head comparison of somatostatin receptor scintigraphy, ${ }^{123} \mathrm{I}$ MIBG scintigraphy, and ${ }^{18}$ F-FDG PET. J Nucl Med 2010;51:704-712.

-6 Rindi G, Klöppel G, Alhman H, Caplin M, Couvelard A, de Herder WW, Eriksson B, Falchetti A, Falconi M, Komminoth P, Körner M, Lopes JM, McNicol AM, Nilsson O, Perren A, Scarpa A, Scoazec JY, Wiedenmann B; all other Frascati Consensus Conference participants; European Neuroendocrine Tumor Society (ENETS): TNM staging of foregut (neuro)endocrine tumors: a consensus proposal including a grading system. Virchows Arch 2006;449:395-401.

7 Salazar R, Wiedenmann B, Rindi G, Ruszniewski P: ENETS 2011 Consensus Guidelines for the Management of Patients with Digestive Neuroendocrine Tumors: an update. Neuroendocrinology 2012;95:71-73.

8 Bosman F, Carneiro F, Hruban RH, Theise ND: WHO Classification of Tumours of the Digestive System; in Bosman F, Jaffe ES, Lakhani SR, Ohgaki H (ed): WHO Classification of Tumours. Lyon, IARC Press, 2010.

$>9$ Kvols LK, Brendtro KL; North American Neuroendocrine Tumor Society (NANETS): The North American Neuroendocrine Tumor Society (NANETS) guidelines: mission, goals, and process. Pancreas 2010;9:705706.

10 Klimstra DS, Modlin IR, Adsay NV, Chetty R, Deshpande V, Gönen M, Jensen RT, Kidd M, Kulke MH, Lloyd RV, Moran C, Moss SF, Oberg K, O’Toole D, Rindi G, Robert ME, Suster S, Tang LH, Tzen CY, Washington MK, Wiedenmann B, Yao J: Pathology reporting of neuroendocrine tumors: application of the Delphic consensus process to the development of a minimum pathology data set. Am J Surg Pathol 2010;34:300-313.

-11 Strosberg J, Nasir A, Coppola D, Wick M, Kvols L: Correlation between grade and prognosis in metastatic gastroenteropancreatic neuroendocrine tumors. Hum Pathol 2009; 40:1262-1268.

12 Mengel M, von Wasielewski R, Wiese B, Rüdiger T, Müller-Hermelink HK, Kreipe H: Inter-laboratory and inter-observer reproducibility of immunohistochemical assessment of the Ki-67 labelling index in a large multi-centre trial. J Pathol 2002;198:292-299.

-13 Scarpa A, Mantovani W, Capelli P, Beghelli S, Boninsegna L, Bettini R, Panzuto F, Pederzoli P, delle Fave G, Falconi M: Pancreatic endocrine tumors: improved TNM staging and histopathological grading permit a clinically efficient prognostic stratification of patients. Mod Pathol 2010;23:824-833.

14 Reubi JC: Peptide receptors as molecular targets for cancer diagnosis and therapy. Endocr Rev 2003;24:389-427.
15 Gabriel M, Decristoforo C, Kendler D, Dobrozemsky G, Heute D, Uprimny C, Kovacs P, Von Guggenberg E, Bale R, Virgolini IJ: 68Ga-DOTA-Tyr3-octreotide PET in neuroendocrine tumors: comparison with somatostatin receptor scintigraphy and CT. J Nucl Med 2007;48:508-518.

16 Kwekkeboom DJ, de Herder WW, Kam BL, van Eijck CH, van Essen M, Kooij PP, Feelders RA, van Aken MO, Krenning EP: Treatment with the radiolabeled somatostatin analog [177 Lu-DOTA 0, Tyr3] octreotate: toxicity, efficacy, and survival. J Clin Oncol 2008;6: 2124-2130.

17 Waser B, Rehmann R, Sanchez C, Fourmy D, Reubi JC: Glucose-dependent insulinotropic polypeptide receptors in most gastroenteropancreatic and bronchial neuroendocrine tumors. J Clin Endocrinol Metab 2012;97:482488 .

18 Gourni E, Waser B, Clerc P, Fourmy D, Reubi JC, Maecke HR: the glucose-dependent insulinotropic polypeptide receptor: a novel target for neuroendocrine tumor imagingfirst preclinical studies. J Nucl Med 2014;55: 976-982.

19 Abgral R, Leboulleux S, Déandreis D, Aupérin A, Lumbroso J, Dromain C, Duvillard P, Elias D, de Baere T, Guigay J, Ducreux M, Schlumberger M, Baudin E: Performance of (18)fluorodeoxyglucose-positron emission tomography and somatostatin receptor scintigraphy for high $\mathrm{Ki} 67$ ( $\geq 10 \%$ ) well-differentiated endocrine carcinoma staging. J Clin Endocrinol Metab 2011;96:665-671.

20 Pavel M, Baudin E, Couvelard A, Krenning E, Öberg K, Steinmüller T, Anlauf M, Wiedenmann B, Salazar R; Barcelona Consensus Conference participants: ENETS Consensus Guidelines for the management of patients with liver and other distant metastases from neuroendocrine neoplasms of foregut, midgut, hindgut, and unknown primary. Neuroendocrinology 2012;95:157-176.

21 Christ E, Wild D, Forrer F, Brändle M, Sahli R, Clerici T, Gloor B, Martius F, Maecke HR, Reubi JC: Glucagon-like peptide-1 receptor imaging for localization of insulinomas. J Clin Endocrinol Metab 2009;94:4398-4405. 
22 Reubi JC, Läderach U, Waser B, Gebbers JO, Robberecht P, Laissue JA: Vasoactive intestinal peptide/pituitary adenylate cyclase-activating peptide receptor subtypes in human tumors and their tissues of origin. Cancer Res 2000;60:3105-3112.

-23 Körner M, Stöckli M, Waser B, Reubi JC: GLP-1 receptor expression in human tumors and human normal tissues: potential for in vivo targeting. J Nucl Med 2007;48:736-743.

-24 Körner M, Waser B, Schonbrunn A, Perren A, Reubi JC: Somatostatin receptor subtype 2A immunohistochemistry using a new monoclonal antibody selects tumors suitable for in vivo somatostatin receptor targeting. Am J Surg Pathol 2012;36:242-252.

-25 Rindi G, Klöppel G, Couvelard A, Komminoth P, Körner M, Lopes JM, McNicol AM, Nilsson O, Perren A, Scarpa A, Scoazec JY, Wiedenmann B: TNM staging of midgut and hindgut (neuro) endocrine tumors: a consensus proposal including a grading system. Virchows Arch 2007;451:757-762.

-26 Zahel T, Krysa S, Herpel E, Stenzinger A, Goeppert B, Schirmacher P, Hoffmann $\mathrm{H}$, Schnabel PA, Warth A: Phenotyping of pulmonary carcinoids and a Ki-67-based grading approach. Virchows Arch 2012;460:299-308.
27 Reubi JC, Kvols LK, Waser B, Nagorney DM, Heitz PU, Charboneau JW, Reading CC, Moertel C: Detection of somatostatin receptors in surgical and percutaneous needle biopsy samples of carcinoids and islet cell carcinomas. Cancer Res 1990;50:5969-5977.

28 Baskin DG, Wimpy TH: Calibration of [14C] plastic standards for quantitative autoradiography of [125I]labeled ligands with Amersham Hyperfilm beta-max. Neurosci Lett 1989; 104:171-177.

29 Miller JA, Zahniser NR: The use of 14C-labeled tissue paste standards for the calibration of ${ }^{125}$ I-labeled ligands in quantitative autoradiography. Neurosci Lett 1987;81:345-350.

30 Krenning EP, Kwekkeboom DJ, Pauwels S, Kvols LK, Reubi JC: Somatostatin receptor scintigraphy; in Freeman LM (ed): Nuclear Medicine Annual. New York, Raven Press, 1995, pp 1-50.

-31 Reubi JC, Waser B: Concomitant expression of several peptide receptors in neuroendocrine tumours: molecular basis for in vivo multireceptor tumour targeting. Eur J Nucl Med Mol Imaging 2003;30:781-793.
2 Vélayoudom-Céphise FL, Duvillard P, Foucan L, Hadoux J, Chougnet CN, Leboulleux S, Malka D, Guigay J, Goere D, Debaere T, Caramella C, Schlumberger M, Planchard D, Elias D, Ducreux M, Scoazec JY, Baudin E: Are G3 ENETS neuroendocrine neoplasms heterogeneous? Endocr Relat Cancer 2013;20: 649-657.

33 Mazzuco TL, Chabre O, Feige JJ, Thomas M: Aberrant GPCR expression is a sufficient genetic event to trigger adrenocortical tumorigenesis. Mol Cell Endocrinol 2007;265-266: 23-28.

34 Prabakaran D, Wang B, Feuerstein JD, Sinclair JA, Bijpuria P, Jepeal LI, Wolfe MM: Glucose-dependent insulinotropic polypeptide stimulates the proliferation of colorectal cancer cells. Regul Pept 2010;163:74-80.

35 Körner M, Eltschinger V, Waser B, Schonbrunn A, Reubi JC: Value of immunohistochemistry for somatostatin receptor subtype sst2A in cancer tissues: lessons from the comparison of anti-sst2A antibodies with somatostatin receptor autoradiography. Am J Surg Pathol 2005;29:1642-1651. 